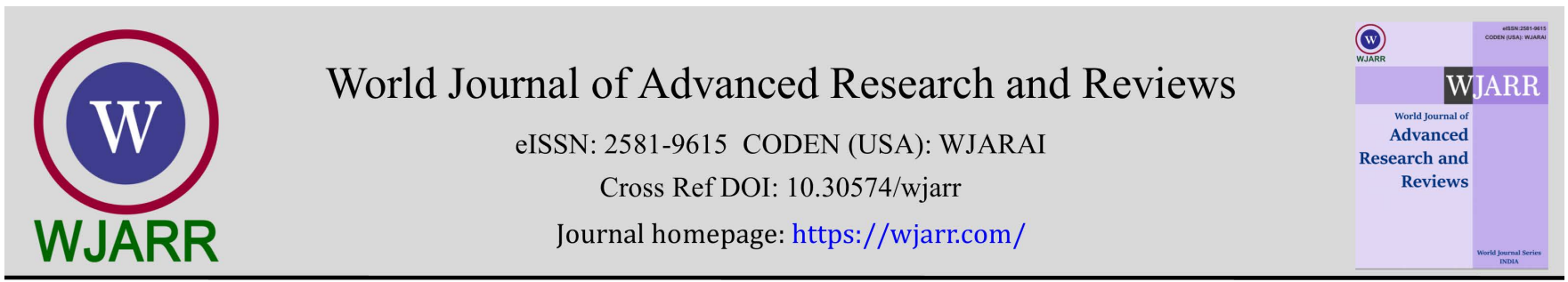

(RESEARCH ARTicle)

Check for updates

\title{
Remission of comorbidities, weight loss, and adverse events after sleeve gastrectomy and Roux-en-Y Gastric Bypass in patients with obesity
}

\author{
Omar Thaher 1, ${ }^{*}$, Jamal Driouch ${ }^{1}$, Martin Hukauf ${ }^{2}$ and Christine Stroh ${ }^{3}$ \\ ${ }^{1}$ Department of Surgery, Marien Hospital Herne, Ruhr-Universität Bochum, Hölkeskampring 40, 44625 Herne, Germany. \\ 2 StatConsult gGmbH, Am Fuchsberg 11, 39112 Magdeburg, German. \\ 3 Department of General, Abdominal and Pediatric, Surgery, Municipal Hospital, Straße des Friedens 122, 07548 Gera, \\ Germany.
}

World Journal of Advanced Research and Reviews, 2021, 12(03), 251-263

Publication history: Received on 03 November 2021; revised on 13 December 2021; accepted on 15 December 2021

Article DOI: https://doi.org/10.30574/wjarr.2021.12.3.0682

\begin{abstract}
Background: Despite the extensive literature on the outcome and impact of Roux-en-Y gastric bypass (RYGB) and sleeve gastrectomy (SG) on comorbidities and weight loss, clear evidence is still lacking. Our study aims to compare the short- and long-term efficacy and safety of the two procedures in patients with obesity.
\end{abstract}

Methods: The primary endpoint of this retrospective registry study is to examine the adverse events after surgery, weight loss, and remission rate of comorbidities 12 months after surgery. Any result with a p-value of $\leq 5 \%$ corresponds to a significant outcome.

Results: 27,882 patients had completed a one-year follow-up. 14,399 patients after SG and 13,483 after RYGB. The overall rate of intraoperative and postoperative complications was not significantly different between the two groups (overall p>5\%). The \%EWL was $62.4 \%$ in the SG group vs. $69.2 \%$ in the RYGB group; $\mathrm{p}<0.001$. BMI reduction and mean weight loss were significantly different between the two groups in favor of SG.

The RYGB group achieved significantly better remission of diabetes mellitus (T2DM; $<<0.001$ ), hypertension (28.8\% vs. $23.5 \%$; $p<0.001$ ) and reflux $22.3 \%$ vs. $7.8 \%$; $<0.001$ ). Sleep apnea remission was similar between the two groups $(10.2 \% ; \mathrm{p}<0.001)$.

Conclusion: SG and RYGB are effective methods in the treatment of obesity. RYGB achieved better results in terms of remission of comorbidities and \%EWL. However, further studies are needed to investigate the sustainability of weight loss and remission of comorbidities after both procedures.

Keywords: Sleeve gastrectomy; Gastric bypass; Morbidity; Comorbidities; One-year follow-up

\section{Introduction}

Despite the advanced health care and tremendous development in medicine, some diseases such as obesity and cardiopulmonary diseases still pose a medical challenge. This development leads to an additional burden on the health and economic system and the health damage and reduction in the quality of life of the affected patients [1;2].

\footnotetext{
* Corresponding author: Omar Thaher

Department of Surgery, Marien Hospital Herne, Ruhr-Universität Bochum, Hölkeskampring 40, 44625 Herne, Germany.

Copyright @ 2021 Author(s) retain the copyright of this article. This article is published under the terms of the Creative Commons Attribution Liscense 4.0.
} 
Several studies have shown that bariatric surgery achieves more effective results in the remission of comorbidities than conservative therapy [3; 4]. However, diverse bariatric surgical methods differ significantly in the remission of comorbidities and perioperative outcomes $[5 ; 6]$.

Our study aims to compare the effects of two well-known bariatric surgical procedures, namely sleeve gastrectomy (SG) and Roux-en-Y gastric bypass (RYGB), on remission of comorbidities and perioperative outcomes.

Each of the two procedures has its advantages and disadvantages. Because of its technical simplicity and associated low complication rate, SG has quickly become one of the most popular bariatric surgical procedures in treating patients with obesity [7]. However, when bariatric surgical therapy aims to treat obesity-associated diseases, surgical methods such as RYGB showed better results than SG [8].

Despite the advantages of both surgical methods, to date, there is no direct recommendation in favor of either method regarding the development of comorbidities and long-term impact on weight loss. The indication remains controversial and needs further support from scientific studies and guidelines.

\section{Material and methods}

Our multicenter study included 54,984 patients with morbid obesity according to primary SG and RYGB. 27,882 patients had completed the one-year follow-up period with final data export in April 2021. The present study focused exclusively on perioperative outcomes and one-year follow-up results. The main inclusion criteria for the analysis population were:

- A minimum age of 18 years,

- A primary procedure using the RYGB or SG technique, and

- Availability of data at the time of one-year follow-up.

All patients were examined and asked to consent to data entry into the GBSR preoperatively. Data collected included demographic data and preoperative and postoperative measurements. In addition, information on comorbidities was collected and documented preoperatively as well. We assumed that a patient suffered from diabetes mellitus (T2DM), hypertension, sleep apnea (SA), and reflux disease (GERD) if the patient had a documented preoperative diagnosis or was taking medications preoperatively for any of these conditions. After surgery, remission of T2DM was defined as normal or near-normal blood glucose levels and or discontinuation of hypoglycemic medications. Our analysis did not consider HbA1c level as a parameter for the remission of T2DM. Remission of hypertension was reported when patients had normal blood pressure after surgery or discontinuation of antihypertensive medication. This was also true for patients with reflux and sleep apnea. Intraoperative and postoperative complications were also recorded. During follow-up, patient data were calculated and documented in terms of percentage excess weight loss (\%EWL), body mass index (BMI) reduction, and remission of comorbidities within the appropriate time.

With one exception, patients were selected for RYGB or SG treatment based on patient characteristics and weight center provider consensus. In addition, because this is a registry data collection, we cannot describe the surgical steps for RYGB and SG. It depends on the surgeon and their expertise as to which method to use during the procedure.

All analyzes were performed using SAS 9.4 software (SAS Institute Inc., Cary, NC, USA). Because this was an exploratory analysis, tests were intentionally performed at the full $5 \%$ significance level, i.e., there is no correction for multiple testing, and any p-value of $5 \%$ corresponds to a significant result.

The study was conducted following the recommendations of the Declaration of Helsinki for biomedical research. Before entering the data into the registry, all participants signed the informed consent form and consent.

\subsection{Data preparation}

Individual variables are not explicitly listed but must be derived from the data. These relate to:

- Comorbidities, intraoperative, general, and specific postoperative complications are recorded individually and combined into one variable, e.g., intraoperative complications are reported if at least one intraoperative complication is selected.

- Follow-up period: one year - considering a visit window of 182 to 547 days after surgery.

- BMI reduction: the difference between BMI at baseline and BMI at follow-up. 
- \%EWL: ratio of weight loss to excess weight as a percentage, where excess weight is defined as the difference between weight and ideal weight (based on height and BMI = 25) at baseline.

\subsection{Descriptive statistics, univariates / unadjusted analyses:}

For the distributions of (quasi-) continuous variables, the mean and standard deviation (STD) or the range of dispersion for log-transformed data are given. For categorical variables, absolute (N) and relative (\%) frequencies are reported.

For unadjusted analyzes of surgical interventions, the chi-square test was used for categorical variables and the robust t-test (Satterthwaite) for continuous variables.

\section{Results}

We analyzed data from 27,882 patients from January 2005 to April 2021 who completed a one-year follow-up after primary SG or RYGB. Over 98\% of RYGB and SG procedures were performed laparoscopically (Table 1; 2).

Table 1 Distribution of surgical method at the time of primary surgery and at one-year follow-up

\begin{tabular}{|l|c|c|c|c|}
\hline \multirow{2}{*}{ Method } & \multicolumn{2}{|c|}{ At time of surgery } & \multicolumn{2}{c|}{ One-year follow-up } \\
\cline { 2 - 5 } & $\mathbf{N}$ & $\mathbf{\%}$ & $\mathbf{N}$ & $\mathbf{\%}$ \\
\hline SG & 27854 & 50.7 & 14399 & 51.6 \\
\hline RYGB & 27130 & 49.3 & 13483 & 48.4 \\
\hline Total & 54984 & 100 & 27882 & 100 \\
\hline
\end{tabular}

Table 2 Type of surgery and operating time for patients who had completed the one-year follow-up

\begin{tabular}{|l|c|c|c|c|c|}
\hline \multirow{2}{*}{} & \multicolumn{4}{|c|}{ Method } \\
\cline { 2 - 6 } & \multicolumn{3}{|c|}{ SG } & \multicolumn{3}{c|}{ RYGB } \\
\cline { 2 - 5 } & $\mathbf{N}$ & $\%$ & N & \% & p-value \\
\hline Laparotomy & 89 & 0.6 & 112 & 0.8 & 0.035 \\
\hline Laparoscopy & 14231 & 99.1 & 13294 & 98.7 & \\
\hline Conversion & 46 & 0.3 & 58 & 0.4 & \\
\hline Operating time [min]* & $14356 / 78.9$ & $13473 / 102.1$ & $<0.001$ \\
(mean [range of dispersion]) & {$[74.7 ; 83.0]$} & {$[97.0 ; 107.2]$} & \\
\hline
\end{tabular}

Table 3 Distribution of demographic variables at the time of surgery and at one-year follow-up

\begin{tabular}{|c|c|c|c|c|}
\hline & & \multicolumn{2}{|c|}{ Method } & \multirow[t]{2}{*}{ p-value } \\
\hline & & SG & RYGB & \\
\hline $\begin{array}{l}\text { Age (years) } \\
\text { (At time of surgery) }\end{array}$ & $\mathrm{N} /$ mean value $\pm \mathrm{STD}$ & $14399 / 43.7 \pm 11.4$ & $13483 / 43.3 \pm 11.2$ & $<0.001$ \\
\hline $\begin{array}{l}\text { BMI } \\
\mathrm{Kg} / \mathrm{m}^{2} \\
\text { (At time of surgery) }\end{array}$ & $\mathrm{N} /$ mean value $\pm \mathrm{STD}$ & 14389 / $51.3 \pm 9.1$ & $13471 / 47.8 \pm 7.0$ & $<0.001$ \\
\hline Gender & $\%$ & $32.9 / 67.1$ & $21.2 / 78.8$ & $<0.001$ \\
\hline
\end{tabular}


The

\begin{tabular}{|l|l|c|c|c|}
\hline & $(\mathrm{N})$ & $4732 / 9667$ & $2860 / 10623$ & \\
\hline \multicolumn{2}{|l|}{ Mean weight loss, BMI reduction and \%EWL at one-year follow-up } \\
\hline$\%$ EWL & $\mathrm{N} /$ mean value \pm STD & $14362 / 62.4 \pm 22.6$ & $13445 / 69.2 \pm 21.5$ & $<0.001$ \\
\hline BMI reduction $\left(\mathrm{Kg} / \mathrm{m}^{2}\right)$ & $\mathrm{N} /$ mean value \pm STD & $14291 / 15.5 \pm 5.9$ & $13348 / 15.2 \pm 5.0$ & $<0.001$ \\
& & & & \\
\hline Mean weight loss $(\mathrm{kg})$ & $\mathrm{N} /$ mean value \pm STD & $14365 / 45.6 \pm 18.0$ & $13451 / 43.6 \pm 14.9$ & $<0.001$ \\
& & & & \\
\hline
\end{tabular}

distribution of age showed significant results between the two groups. Sleeve gastrectomy patients were 0.4 years older than RYGB patients ( $43.7 \pm 11.4$ vs. $43.3 \pm 11.2$; $\mathrm{p}<0.001$ ). Regarding gender, the proportion of females was significantly greater than the proportion of males in both groups (67.1\% female vs. $32.9 \%$ male in the SG and $78.8 \%$ female vs. 21.2 male in the RYGB; $\mathrm{p}<0.001$ ) (Table 3).

\subsection{Comorbidities}

While ASA II was documented more frequently in the RYGB group, ASA III was more common in the SG group ( $p<0.001)$. The percentage distribution of comorbidities was significantly higher in the SG group than in the RYGB group (92\% in the SG group vs. $89.7 \%$ in the RYGB group; $\mathrm{p}<0.001$ ). More patients in the RYGB group suffered from T2DM than patients in the SG group (36.8\% vs. $33.3 \%$; $<<0.001)$. This was also true for reflux disease $(24 \%$ vs. $11 \%$; $<<0.001)$. In contrast, more patients in the SG group suffered from hypertension $(63.9 \%$ vs. $60.3 \%$; p < 0.001$)$ and sleep apnea $(28.3 \%$ vs. 21.8\%; $\mathrm{p}<0.001$ ). A detailed overview of comorbidities can be found in Table 4.

Table 4 Distribution of comorbidities

\begin{tabular}{|c|c|c|c|c|c|c|}
\hline & & \multicolumn{4}{|c|}{ Method } & \multirow[t]{3}{*}{ p-value } \\
\hline & & \multicolumn{2}{|c|}{ SG } & \multicolumn{2}{|c|}{ RYGB } & \\
\hline & & $\mathbf{N}$ & $\%$ & $\mathbf{N}$ & $\%$ & \\
\hline \multirow[t]{4}{*}{ ASA } & ASA I & 585 & 4.1 & 267 & 2.0 & \multirow[t]{4}{*}{$<0.001$} \\
\hline & ASA II & 5952 & 41.4 & 7235 & 53.8 & \\
\hline & ASA III & 7525 & 52.3 & 5814 & 43.2 & \\
\hline & ASA IV & 314 & 2.2 & 140 & 1.0 & \\
\hline \multirow[t]{2}{*}{ Comorbidities (total) } & Yes & 13244 & 92.0 & 12089 & 89.7 & \multirow[t]{2}{*}{$<0.001$} \\
\hline & No & 1155 & 8.0 & 1394 & 10.3 & \\
\hline \multirow[t]{2}{*}{ Diabetes (total) T2DM } & Yes & 4427 & 33.3 & 4635 & 36.8 & \multirow[t]{2}{*}{$<0.001$} \\
\hline & No & 8864 & 66.7 & 7966 & 63.2 & \\
\hline \multirow[t]{2}{*}{ T2DM (IDDM) } & Yes & 1410 & 10.6 & 1465 & 11.6 & \multirow[t]{2}{*}{0.009} \\
\hline & No & 11881 & 89.4 & 11136 & 88.4 & \\
\hline \multirow[t]{2}{*}{ T2DM (NIDDM) } & Yes & 2406 & 18.1 & 2575 & 20.4 & \multirow[t]{2}{*}{$<0.001$} \\
\hline & No & 10885 & 81.9 & 10026 & 79.6 & \\
\hline \multirow[t]{2}{*}{ T2DM (dietary) } & Yes & 611 & 4.6 & 595 & 4.7 & \multirow[t]{2}{*}{0.634} \\
\hline & No & 12680 & 95.4 & 12006 & 95.3 & \\
\hline \multirow[t]{2}{*}{ Arterial hypertension } & Yes & 9206 & 63.9 & 8127 & 60.3 & \multirow[t]{2}{*}{$<0.001$} \\
\hline & No & 5193 & 36.1 & 5356 & 39.7 & \\
\hline \multirow[t]{2}{*}{ Pulmonary } & Yes & 2975 & 20.7 & 2481 & 18.4 & \multirow[t]{2}{*}{$<0.001$} \\
\hline & No & 11424 & 79.3 & 11002 & 81.6 & \\
\hline \multirow[t]{2}{*}{ Pulmonary embolism } & Yes & 166 & 1.2 & 88 & 0.7 & \multirow[t]{2}{*}{$<0.001$} \\
\hline & No & 14233 & 98.8 & 13395 & 99.3 & \\
\hline \multirow[t]{2}{*}{ Other cardiac and vascular diseases (OCVD) } & Yes & 1562 & 10.8 & 1064 & 7.9 & \multirow[t]{2}{*}{$<0.001$} \\
\hline & No & 12837 & 89.2 & 12419 & 92.1 & \\
\hline
\end{tabular}




\begin{tabular}{|c|c|c|c|c|c|c|}
\hline & & \multicolumn{4}{|c|}{ Method } & \multirow[t]{3}{*}{ p-value } \\
\hline & & \multicolumn{2}{|c|}{ SG } & \multicolumn{2}{|c|}{ RYGB } & \\
\hline & & $\mathbf{N}$ & $\%$ & $\mathbf{N}$ & $\%$ & \\
\hline \multirow[t]{2}{*}{ Cholecystolithiasis } & Yes & 530 & 3.7 & 561 & 4.2 & \multirow[t]{2}{*}{0.039} \\
\hline & No & 13869 & 96.3 & 12922 & 95.8 & \\
\hline \multirow[t]{2}{*}{ Reflux } & Yes & 1590 & 11.0 & 3233 & 24.0 & \multirow[t]{2}{*}{$<0.001$} \\
\hline & No & 12809 & 89.0 & 10250 & 76.0 & \\
\hline \multirow[t]{2}{*}{ Lymphedema } & Yes & 891 & 6.2 & 961 & 7.1 & \multirow[t]{2}{*}{0.002} \\
\hline & No & 13508 & 93.8 & 12522 & 92.9 & \\
\hline \multirow[t]{2}{*}{ Degenerative diseases of the skeletal system (DSD) } & Yes & 6894 & 47.9 & 5269 & 39.1 & \multirow[t]{2}{*}{$<0.001$} \\
\hline & No & 7505 & 52.1 & 8214 & 60.9 & \\
\hline \multirow[t]{2}{*}{ Orthopedic therapy } & Yes & 3978 & 27.6 & 2946 & 21.8 & \multirow[t]{2}{*}{$<0.001$} \\
\hline & No & 10421 & 72.4 & 10537 & 78.2 & \\
\hline \multirow[t]{2}{*}{ Degenerative spine diseases } & Yes & 5163 & 35.9 & 4765 & 35.3 & \multirow[t]{2}{*}{0.369} \\
\hline & No & 9236 & 64.1 & 8718 & 64.7 & \\
\hline \multirow[t]{2}{*}{ Gonarthrose } & Yes & 3500 & 24.3 & 3103 & 23.0 & \multirow[t]{2}{*}{0.011} \\
\hline & No & 10899 & 75.7 & 10380 & 77.0 & \\
\hline \multirow[t]{2}{*}{ Coxarthrose } & Yes & 902 & 6.3 & 849 & 6.3 & \multirow[t]{2}{*}{0.911} \\
\hline & No & 13497 & 93.7 & 12634 & 93.7 & \\
\hline \multirow[t]{2}{*}{ Smoking } & Yes & 1380 & 9.6 & 1548 & 11.5 & \multirow[t]{2}{*}{$<0.001$} \\
\hline & No & 13019 & 90.4 & 11935 & 88.5 & \\
\hline \multirow[t]{2}{*}{ Varicoses } & Yes & 775 & 5.4 & 1025 & 7.6 & \multirow[t]{2}{*}{$<0.001$} \\
\hline & No & 13624 & 94.6 & 12458 & 92.4 & \\
\hline \multirow[t]{2}{*}{ Non-Alcoholic Steatohepatitis (NASH) } & Yes & 599 & 5.4 & 780 & 8.2 & $<0.001$ \\
\hline & No & 10594 & 94.6 & 8757 & 91.8 & \\
\hline Alcohol & Yes & 193 & 1.3 & 136 & 1.0 & 0.010 \\
\hline & No & 14206 & 98.7 & 13347 & 99.0 & \\
\hline Pseudotumor Cerebri & Yes & 33 & 0.3 & 23 & 0.2 & 0.458 \\
\hline & No & 11160 & 99.7 & 9514 & 99.8 & \\
\hline Rheumatoid inflammatory diseases (RID) & Yes & 153 & 1.4 & 97 & 1.0 & 0.021 \\
\hline & No & 11039 & 98.6 & 9440 & 99.0 & \\
\hline Polycystic ovary syndrome (PCOS) & Yes & 174 & 2.3 & 175 & 2.3 & 0.919 \\
\hline & No & 7391 & 97.7 & 7352 & 97.7 & \\
\hline Chronic inflammatory gastrointestinal diseases (CIGD) & Yes & 49 & 0.4 & 8 & $<0.1$ & $<0.001$ \\
\hline & No & 11143 & 99.6 & 9530 & $>99.9$ & \\
\hline Hypogonadism & Yes & 25 & 0.7 & 17 & 0.8 & 0.513 \\
\hline & No & 3602 & 99.3 & 1993 & 99.2 & \\
\hline Transplantation & Yes & 16 & 0.1 & 5 & $<0.1$ & 0.041 \\
\hline & No & 11176 & 99.9 & 9532 & $>99.9$ & \\
\hline Sleep apnea & Yes & 4070 & 28.3 & 2939 & 21.8 & $<0.001$ \\
\hline & No & 10329 & 71.7 & 10544 & 78.2 & \\
\hline
\end{tabular}

\subsection{Adverse Events:}


Evaluation of the overall intraoperative complication rate showed no significant difference between SG and RYGB $(\mathrm{p}=0.686)$. At least one intraoperative complication occurred in 200 patients after SG and 195 after RYGB. Analysis of individual complications showed significant results regarding splenic injury with a higher incidence in the SG group $(0.3 \%$ in the SG group vs. $0.1 \%$ in the RYGB group; $\mathrm{p}=0.002)$. Other individual complications analyzed were not significantly different between the two groups (overall $\mathrm{p}>5 \%$ ).

Table 5 Intraoperative complications reported for Sleeve Gastrectomy and Roux-en-Y Gastric Bypass

\begin{tabular}{|c|c|c|c|c|c|c|}
\hline & \multicolumn{4}{|c|}{ Method } & \multirow[t]{3}{*}{ p-value } \\
\hline & & \multicolumn{2}{|c|}{ SG } & \multicolumn{2}{|c|}{ RYGB } & \\
\hline & & $\mathbf{N}$ & $\%$ & $\mathbf{N}$ & $\%$ & \\
\hline \multirow[t]{2}{*}{ Intraoperative complication (total) } & Yes & 200 & 1.4 & 195 & 1.4 & \multirow[t]{2}{*}{0.686} \\
\hline & No & 14199 & 98.6 & 13288 & 98.6 & \\
\hline \multirow[t]{2}{*}{ Injury of splenic } & Yes & 43 & 0.3 & 17 & 0.1 & \multirow[t]{2}{*}{0.002} \\
\hline & No & 14356 & 99.7 & 13466 & 99.9 & \\
\hline \multirow[t]{2}{*}{ Injury of liver } & Yes & 14 & $<0.1$ & 4 & $<0.1$ & \multirow[t]{2}{*}{0.026} \\
\hline & No & 14385 & $>99.9$ & 13479 & $>99.9$ & \\
\hline \multirow[t]{2}{*}{ Pneumothorax } & Yes & 4 & $<0.1$ & 0 & 0 & \multirow[t]{2}{*}{0.053} \\
\hline & No & 14395 & $>99.9$ & 13483 & 100 & \\
\hline \multirow[t]{2}{*}{ Perforation of the stomach } & Yes & 10 & $<0.1$ & 5 & $<0.1$ & \multirow[t]{2}{*}{0.244} \\
\hline & No & 14389 & $>99.9$ & 13478 & $>99.9$ & \\
\hline \multirow[t]{2}{*}{ Bile duct injury } & Yes & 1 & $<0.1$ & 1 & $<0.1$ & \multirow[t]{2}{*}{0.963} \\
\hline & No & 14398 & $>99.9$ & 13482 & $>99.9$ & \\
\hline \multirow[t]{2}{*}{ Vascular injury } & Yes & 7 & $<0.1$ & 5 & $<0.1$ & \multirow[t]{2}{*}{0.643} \\
\hline & No & 14392 & $>99.9$ & 13478 & $>99.9$ & \\
\hline \multirow[t]{2}{*}{ Bleeding } & Yes & 5 & $<0.1$ & 2 & $<0.1$ & \multirow[t]{2}{*}{0.295} \\
\hline & No & 14394 & $>99.9$ & 13481 & $>99.9$ & \\
\hline \multirow[t]{2}{*}{ Other } & Yes & 137 & 1.0 & 168 & 1.2 & \multirow[t]{2}{*}{0.018} \\
\hline & No & 14262 & 99.0 & 13315 & 98.8 & \\
\hline
\end{tabular}

Table 6 General and special postoperative complications reported for Sleeve Gastrectomy and Roux-en-Y Gastric Bypass

\begin{tabular}{|c|c|c|c|c|c|c|}
\hline & & \multicolumn{4}{|c|}{ Method } & \multirow{3}{*}{ p-value } \\
\hline & & \multicolumn{2}{|c|}{ SG } & \multicolumn{2}{|c|}{ RYGB } & \\
\hline & & $\mathbf{N}$ & $\%$ & $\mathrm{~N}$ & $\%$ & \\
\hline \multicolumn{7}{|c|}{ General postoperative complication } \\
\hline \multirow[t]{2}{*}{ Total } & Yes & 580 & 4.0 & 497 & 3.7 & \multirow[t]{2}{*}{0.139} \\
\hline & No & 13819 & 96.0 & 12986 & 96.3 & \\
\hline \multirow[t]{2}{*}{ Urinary tract infection } & Yes & 101 & 0.7 & 60 & 0.4 & \multirow[t]{2}{*}{0.005} \\
\hline & No & 14298 & 99.3 & 13423 & 99.6 & \\
\hline \multirow[t]{2}{*}{ Cardiac complication } & Yes & 50 & 0.3 & 43 & 0.3 & \multirow[t]{2}{*}{0.682} \\
\hline & No & 14349 & 99.7 & 13440 & 99.7 & \\
\hline \multirow[t]{2}{*}{ Renal complication } & Yes & 30 & 0.2 & 20 & 0.1 & \multirow[t]{2}{*}{0.237} \\
\hline & No & 14369 & 99.8 & 13463 & 99.9 & \\
\hline \multirow[t]{2}{*}{ Pulmonary complication } & Yes & 97 & 0.7 & 67 & 0.5 & \multirow[t]{2}{*}{0.054} \\
\hline & No & 14302 & 99.3 & 13416 & 99.5 & \\
\hline
\end{tabular}




\begin{tabular}{|c|c|c|c|c|c|c|}
\hline & & \multicolumn{4}{|c|}{ Method } & \multirow[t]{3}{*}{ p-value } \\
\hline & & \multicolumn{2}{|c|}{ SG } & \multicolumn{2}{|c|}{ RYGB } & \\
\hline & & $\mathbf{N}$ & $\%$ & $\mathbf{N}$ & $\%$ & \\
\hline \multicolumn{7}{|c|}{ General postoperative complication } \\
\hline \multirow[t]{2}{*}{ Fever } & Yes & 104 & 0.7 & 99 & 0.7 & \multirow[t]{2}{*}{0.906} \\
\hline & No & 14295 & 99.3 & 13384 & 99.3 & \\
\hline \multirow[t]{2}{*}{ Thrombosis } & Yes & 14 & $<0.1$ & 2 & $<0.1$ & \multirow[t]{2}{*}{0.004} \\
\hline & No & 14385 & $>99.9$ & 13481 & $>99.9$ & \\
\hline \multirow[t]{2}{*}{ Other } & Yes & 314 & 2.2 & 282 & 2.1 & \multirow[t]{2}{*}{0.607} \\
\hline & No & 14085 & 97.8 & 13201 & 97.9 & \\
\hline \multicolumn{7}{|c|}{ Special postoperative complication } \\
\hline \multirow[t]{2}{*}{ Total } & Yes & 490 & 3.4 & 500 & 3.7 & \multirow[t]{2}{*}{0.169} \\
\hline & No & 13909 & 96.6 & 12983 & 96.3 & \\
\hline \multirow[t]{2}{*}{ Bleeding requiring transfusion } & Yes & 100 & 0.7 & 88 & 0.7 & \multirow[t]{2}{*}{0.670} \\
\hline & No & 14299 & 99.3 & 13395 & 99.3 & \\
\hline \multirow[t]{2}{*}{ Bleeding requiring surgery } & Yes & 175 & 1.2 & 92 & 0.7 & \multirow[t]{2}{*}{$<0.001$} \\
\hline & No & 14224 & 98.8 & 13391 & 99.3 & \\
\hline \multirow[t]{2}{*}{ Bleeding requiring endoscopy } & Yes & 50 & 0.3 & 85 & 0.6 & \multirow[t]{2}{*}{$<0.001$} \\
\hline & No & 14349 & 99.7 & 13398 & 99.4 & \\
\hline \multirow[t]{2}{*}{ Staple line and anastomosis leak } & Yes & 125 & 0.9 & 142 & 1.1 & \multirow[t]{2}{*}{0.113} \\
\hline & No & 14274 & 99.1 & 13341 & 98.9 & \\
\hline \multirow[t]{2}{*}{ Stenosis } & Yes & 7 & $<0.1$ & 53 & 0.4 & \multirow[t]{2}{*}{$<0.001$} \\
\hline & No & 14392 & $>99.9$ & 13430 & 99.6 & \\
\hline \multirow[t]{2}{*}{ Ileus } & Yes & 4 & $<0.1$ & 38 & 0.3 & \multirow[t]{2}{*}{$<0.001$} \\
\hline & No & 14395 & $>99.9$ & 13445 & 99.7 & \\
\hline \multirow[t]{2}{*}{ Abscess formation } & Yes & 69 & 0.5 & 40 & 0.3 & \multirow[t]{2}{*}{0.015} \\
\hline & No & 14330 & 99.5 & 13443 & 99.7 & \\
\hline \multirow[t]{2}{*}{ Sepsis } & Yes & 35 & 0.2 & 16 & 0.1 & 0.015 \\
\hline & No & 14364 & 99.8 & 13467 & 99.9 & \\
\hline Peritonitis & Yes & 51 & 0.4 & 53 & 0.4 & 0.594 \\
\hline & No & 14348 & 99.6 & 13430 & 99.6 & \\
\hline Wound infection & Yes & 80 & 0.6 & 76 & 0.6 & 0.928 \\
\hline & No & 14319 & 99.4 & 13407 & 99.4 & \\
\hline
\end{tabular}

Comparison of the total postoperative general and specific complication rates also showed no significant difference between the two groups ( $\mathrm{p}=0.139$ and 0.169 , respectively). However, analysis of individual postoperative complications showed different results between the two groups. While bleeding requiring surgical intervention, abscess formation, and sepsis were more common after SG, bleeding requiring endoscopic intervention, anastomotic stenosis, and the occurrence of ileus were reported more frequently after RYGB $(\mathrm{p}<0.001)$. A summary of intraoperative, general, and specific postoperative complications can be found in Tables 5 and 6 .

\subsection{BMI, weight loss, and \%EWL}

There was a significant difference in mean BMI at baseline between the two groups. Thus, SG patients had a significantly higher BMI (51.3 $\pm 9.1 \mathrm{~kg} / \mathrm{m}^{2}$ vs. $47.8 \pm 7.0$ in the RYGB group; $\left.\mathrm{p}<0.001\right)$. At a one-year follow-up, the mean BMI reduction was $15.5 \pm 5.9 \mathrm{~kg} / \mathrm{m}^{2}$ in the $S G$ group and $15.2 \pm 5.0 \mathrm{~kg} / \mathrm{m}^{2}$ in the RYGB group $(\mathrm{p}<0.001)$. This was also true for mean weight loss with a significantly higher reduction in favor of the $S G$ group ( $45.6 \mathrm{~kg}$ vs. $43.6 \mathrm{~kg} ; \mathrm{p}<0.001$ ). However, \%EWL was significantly higher in the RYGB group than in the SG group (69.2\% vs. 62.4\%; p<0.001). Table 3 
summarizes the distribution of demographic variables and the change in BMI, mean weight loss, and \%EWL at one-year follow-up.

\subsection{Remission on comorbidities}

\subsubsection{Diabetes mellitus type II (T2D):}

At baseline, 4,427 (33.3\%) patients in the SG group and 4,635 (36.8\%) patients in the RYGB group suffered from T2DM. After one year of follow-up, 7.1\% in the RYGB group and 5.9\% in the SG group showed complete remission of insulindependent diabetes mellitus (IDDM; $<<0.001$ ). No change in symptoms and medication adherence was seen in $4.6 \%$ in the RYGB group and $4.8 \%$ in the SG group. De novo of IDDM symptoms was more frequent in the RYGB group than in the SG group (0.8\% vs. $0.6 \%)$.

As for non-insulin-dependent diabetes mellitus (NIDDM), there was also a significant difference between the two groups with a higher rate of complete remission after RYGB compared to SG (16.1\% vs. 12.8\%; p<0.001). No change in NIDDM was found more frequently in the SG group than in the RYGB group (5.3\% vs. 4.3\%). In the present study, changes in blood glucose levels and required medication (insulin) during the one-year follow-up period were considered changes in T2DM. Table 7 presents the remission and change of IDDM and NIDDM according to SG and RYGB after one year.

\subsubsection{Hypertension}

9,206 patients (63.9\%) in the SG group and 8,127 (60.3\%) in the RYGB group were taking antihypertensive medication at baseline. With a p-value of $<0.001$, a significant change in the rate of hypertension was observed after one year. $23.5 \%$ of patients in the SG group and $28.8 \%$ in the RYGB group had complete remission of hypertension at one year ( $\mathrm{p}<0.001)$. No change ( $40.4 \%$ vs. $31.5 \%$ ) and new development of comorbidities (1\% vs. $0.8 \%$ ) were noted more frequently after SG than after RYGB (Table 7).

\subsubsection{Sleep apnea $(S A)$ :}

Sleep apnea was more frequent in the SG group than in the RYGB group at the time of surgery. After one-year, complete remission of sleep apnea was the same in both groups $(10.2 \% ; \mathrm{p}<0.001)$. However, no change in symptoms was noted more frequently after SG than after RYGB (18.1\% after SG vs. 11.6\% after RYGB). This was also true for the recurrence of comorbidities $(0.8 \%$ after SG vs. $0.6 \%$ after RYGB). The detailed results of sleep apnea remission are summarized in Table 7.

\subsubsection{Gastroesophageal reflux (GERD):}

At the time of surgery, more patients (24\%) in the RYGB group had gastroesophageal reflux disease (GERD) than in the SG one (11\%). This distribution also held for the complete remission of symptoms one year after surgery $(22.3 \%$ in the RYGB group versus $7.8 \%$ in the SG group; $\mathrm{p}<0.001$ ). In addition, more patients reported de novo symptoms after SG compared with RYGB (15.6\% vs. 3\%), and no change in GERD symptoms was noted in 3.2\% of patients after SG compared with $1.7 \%$ after RYGB (Table 7 ).

Table 7 Change in comorbidities at one-year follow-up

\begin{tabular}{|c|c|c|c|c|c|c|}
\hline \multirow{2}{*}{\multicolumn{2}{|c|}{ Remission on obesity-associated diseases }} & \multicolumn{4}{|c|}{ Method } & \multirow[t]{3}{*}{ p-value } \\
\hline & & \multicolumn{2}{|l|}{ SG } & \multicolumn{2}{|l|}{ RYGB } & \\
\hline & & $\mathbf{N}$ & $\%$ & $\mathbf{N}$ & $\%$ & \\
\hline \multirow[t]{4}{*}{ IDDM } & Complete remission & 778 & 5.9 & 890 & 7.1 & \multirow{4}{*}{$<0.001$} \\
\hline & De novo development of comorbidity & 81 & 0.6 & 95 & 0.8 & \\
\hline & No change & 632 & 4.8 & 575 & 4.6 & \\
\hline & No comorbidities before and after surgery & 11791 & 88.8 & 11031 & 87.6 & \\
\hline \multirow[t]{3}{*}{ NIDDM } & Complete remission & 1696 & 12.8 & 2026 & 16.1 & \multirow{3}{*}{$<0.001$} \\
\hline & De novo development of comorbidity & 39 & 0.3 & 43 & 0.3 & \\
\hline & No change & 709 & 5.3 & 546 & 4.3 & \\
\hline
\end{tabular}


World Journal of Advanced Research and Reviews, 2021, 12(03), 251-263

\begin{tabular}{|l|l|c|c|c|c|c|}
\hline & No comorbidities before and after surgery & 10838 & 81.6 & 9976 & 79.2 & \\
\hline \multirow{5}{*}{ Hypertension } & Complete remission & 3383 & 23.5 & 3874 & 28.8 & \\
& De novo development of comorbidity & 140 & 1.0 & 108 & 0.8 & \multirow{3}{*}{$<0.001$} \\
\cline { 2 - 6 } & No change & 5815 & 40.4 & 4247 & 31.5 & \\
\cline { 2 - 6 } & No comorbidities before and after surgery & 5052 & 35.1 & 5244 & 38.9 & \\
\hline \multirow{5}{*}{ Sleep apnea } & Complete remission & 1469 & 10.2 & 1378 & 10.2 & \\
& De novo development of comorbidity & 120 & 0.8 & 85 & 0.6 & \multirow{1}{*}{$<0.001$} \\
\cline { 2 - 6 } & No change & 2601 & 18.1 & 1558 & 11.6 & \\
\cline { 2 - 6 } & No comorbidities before and after surgery & 10200 & 70.9 & 10452 & 77.6 & \\
\cline { 2 - 6 } & Complete remission & 1119 & 7.8 & 3005 & 22.3 & \\
\cline { 2 - 6 } & De novo development of comorbidity & 2243 & 15.6 & 409 & 3.0 & \multirow{3}{*}{$<0.001$} \\
\cline { 2 - 6 } & No change & 467 & 3.2 & 226 & 1.7 & \\
\cline { 2 - 6 } & No comorbidities before and after surgery & 10561 & 73.4 & 9833 & 73.0 & \\
\hline
\end{tabular}

\section{Discussion}

Obesity is a global problem with adverse effects on health and the economic system [9]. In affected patients, obesity leads to exacerbation of certain diseases such as diabetes mellitus (T2DM), hypertension, reflux, sleep apnea, and deterioration of patients' quality of life [10]. Moreover, the prevalence of the disease has increased tremendously in recent years, especially in young people and children [11]. According to statistical analyses, the number of people with obesity is expected to increase in the coming years [12]. This increase is due to our modern lifestyle, poor eating habits and lack of exercise.

In addition to the well-known conservative therapeutic measures, which should be exhausted as the first therapeutic option, several surgical methods offer suitable treatment for obesity. However, these vary widely in terms of difficulty and postoperative outcome, and the impact of obesity-related diseases. While many procedures, such as SG, have a simple technical complexity, other surgical methods, such as RYGB, involve a high technical complexity. Nevertheless, the technical complexity of a procedure is not considered the only determining factor in the indication. Instead, longterm therapeutic goals are critical in determining how a patient should be operated on.

Different distributions of demographic variants were found between the two groups, but their impact on the study results was not considered in the analysis. Primarily, the study aims to compare the outcomes of two surgical procedures, namely SG and RYGB, in patients with obesity and to highlight the differences in perioperative outcomes and remission of comorbidities.

The overall distribution of comorbidities was significantly higher in patients in the SG group than in the RYGB group, although the distribution of individual comorbidities, such as T2DM, hypertension, sleep apnea, and reflux differed in the two groups. The distribution of individual intraoperative and postoperative complications showed different distribution patterns between the two groups, although the overall complication rate was not significantly different for both intraoperative and postoperative complications. Our results are comparable with those of other international studies. In the study by Montgomery et al. [13], the same results were shown regarding the overall rate of intraoperative and postoperative complications. This is also true for the study by Topart et al. [14] and the randomized trial by Helmiö et al. [15]. However, other studies have shown fewer complications after SG than after RYGB [16; 17]. The difference between studies in this regard may be the demographic quality of the patients and the technical complexity of RYGB compared with SG. It should be noted that the differences between the two groups are not that far apart, making the occurrence of complications not a determining factor for the indication. The goal of the procedure, and in particular the long-term goal, is more important than consideration of short-term outcomes when determining indications.

The outcome in terms of BMI reduction and \%EWL was significantly different between the two groups. In general, based on our study and other studies, a consistent conclusion could be drawn regarding better \%EWL after RYGB than after SG. In the study by Zilberstein et al. [18], the \%EWL 5 years after surgery was significantly different at $71.04 \%$ after 
RYGB and 52.7\% after SG. One year after surgery, Lee et al. [19] showed a significant difference in \%EWL in favor of RYGB (41.4 $\pm 11.6 \%$ after RYGB vs. $26.7 \pm 27.6 \%$ after SG). BMI reduction was significantly higher one year after surgery after SG than after RYGB. In our study, \%EWL after RYGB was significantly higher one year after surgery than after SG. BMI reduction and mean weight loss were significantly different between the two groups in favor of SG. However, the difference between the two groups was not extremely high, so these results should not be strongly perceived as a recommendation in favor of $\mathrm{SG}$.

Several studies compare RYGB and SG in terms of remission of T2DM. In our study, RYGB showed superiority over SG in T2DM remission, which may have been influenced by better \%EWL. However, the results are contradictory, as some studies show similar results or no significant difference between the two procedures in this regard [20]. The randomized trial by Salminen et al. [21] tended to show better remission of T2DM after RYGB (45\%) than after SG (37\%), but without significant effect. The same results were shown in a meta-analysis of 21 studies with no statistically significant difference between the two groups regarding remission of diabetes mellitus 0.5 to 1.5 years after intervention [22]. In our study, remission of both IDDM and NIDDM was more frequent after RYGB than after SG. In addition, more patients in SG showed no change in disease compared with patients in the RYGB group. The different results of existing studies regarding the postoperative evolution of T2DM depend on several factors, such as disease severity, weight loss after bariatric surgery, and the quality of patients enrolled in the study.

Some systematic review studies and studies with longer follow-up comparing SG with RYGB have shown significant remission of hypertension after RYGB and SG during the first 12 months [23]. However, when comparing the two methods, a more significant remission of hypertension was demonstrated after RYGB than after SG [24]. This is also true for the results of our study. Patients in both groups also experienced remission of hypertension, especially those in the RYGB group. Various scientific studies have shown that remission of hypertension depends not only on the surgical method but also on other factors such as postoperative weight loss, the level of preoperative antihypertensive medication, and the severity of the disease [25; 26$]$.

In several studies, remission and improvement of sleep apnea were more pronounced after bariatric surgery than with conservative therapeutic measures [27; 28]. However, the results of all studies of reduction and elimination of sleep apnea after bariatric surgery vary because of the characteristics of symptoms, duration of follow-up, and diagnostic procedures [29]. Zilberstein et al. [18] showed improvement in sleep apnea after various bariatric surgery methods. However, RYGB was more effective in improving SA than restrictive procedures, such as SG and gastric banding. These results are also consistent with the results of the study by Sakhosh et al. [30].

In contrast to the previous study results, our study showed similar remission rates of sleep apnea after the two procedures. However, we believe our results are due to the short duration of follow-up. Studies with more extended follow-up periods should be performed to detect a significant difference between the two groups.

According to clinical studies, a higher incidence of GERD was observed in patients with obesity than in normal-weight patients [31]. Therefore, several surgical procedures have been developed and changed to prevent the development or exacerbation of reflux disease in the long term. RYGB has been reported in the literature to relieve GERD symptoms, and some bariatric procedures were eventually converted to RYGB for refractory reflux symptoms [32]. In addition, some studies report a higher risk of GERD after this surgical intervention compared with RYGB [33]. A randomized trial by Peterli et al. showed a significant worsening of reflux disease after SG than after RYGB (31.8\% vs. 6.3\%) [34]. Another study by Barr et al. [35] showed that more acid-reducing medications had to be taken 12 months after SG than after RYGB. The results of our study are consistent with the results of the previously mentioned studies. At 12 months after surgery, recurrence of reflux disease was observed in $15.6 \%$ of patients after SG and in 3\% after RYGB. Remission of the disease was observed more frequently after RYGB than after SG. Based on our analysis and the literature results, if reflux disease is present and bariatric surgery is needed, the decision should be made in favor of RYGB surgery over SG.

\section{Conclusion}

The efficacy of bariatric surgery in comorbidities and weight in patients with obesity compared with conservative treatment options has been demonstrated and well documented in several clinical trials. When differentiating the efficacy of each surgical procedure, RYGB consistently has a better outcome in terms of \%EWL, remission rates of diabetes mellitus, hypertension, and reflux.

However, despite the existing studies, there are heterogeneous opinions worldwide about the outcome after the two surgical procedures, as also mentioned in our study. In addition, there is still no clear evidence on which of the two 
methods is suitable for which patient group. The decision still depends on the quality of the patient, the intended goal of the surgery, and the surgeons' skills.

In conclusion, our study shows that both methods are effective in improving comorbidities and reducing BMI, especially compared with conventional medical treatment. However, RYGB has an advantage over SG, especially when considering the long-term outcomes of the two procedures. Our results may perhaps help establish indications. However, it should be noted that further studies with more extended follow-up periods are under consideration and that the decision on how to proceed should be individualized and depends on the patient's medical history. In addition, interdisciplinary decision-making, patient care, and careful education about the advantages and disadvantages of the two surgical procedures are essential for better outcomes and higher patient satisfaction.

\section{Compliance with ethical standards}

\section{Acknowledgments}

We would like to thank Mr. Martin Hukauf for his contributions to the statistical analysis of our data.

\section{Disclosure of conflict of interest}

Martin Hukauf was employed by the company StatConsult GmbH, Magdeburg. The remaining authors declare that the research was conducted in the absence of any commercial or financial relationships that could be construed as a potential conflict of interest.

\section{Statement of ethical approval}

For this type of retrospective study, no formal consent was required. All data were gathered and analyzed in accordance with the privacy and ethical standards of the institutional and national research committee and with the 1964 Helsinki declaration and its later amendments or comparable ethical standards.

\section{Statement of informed consent}

Informed consent was obtained from all individual participants included in the study.

\section{References}

[1] Withrow D, Alter DA. The Economic Burden of Obesity Worldwide: A Systematic Review of the Direct Costs of Obesity. Obes Rev. Feb 2011; 12(2): 131-41.

[2] Tremmel M, Gerdtham UG, Nilsson PM, Saha S. Economic Burden of Obesity: A Systematic Literature Review. Int J Environ Res Public Health. 19 Apr 2017; 14(4): 435.

[3] Major P, Matłok M, Pędziwiatr M, Migaczewski M, Budzyński P, Stanek M, Kisielewski M, Natkaniec M, Budzyński A. Quality of Life After Bariatric Surgery. Obes Surg. Sep 2015; 25(9): 1703-10.

[4] Athyros VG, Tziomalos K, Karagiannis A, Mikhailidis DP. Cardiovascular Benefits of Bariatric Surgery in Morbidly Obese Patients. Obes Rev. Jul 2011; 12(7): 515-24.

[5] Castro MJ, Jimenez JM, Carbajo MA, et al. Long-Term Weight Loss Results, Remission of Comorbidities and Nutritional Deficiencies of Sleeve Gastrectomy (SG), Roux-En-Y Gastric Bypass (RYGB) and One-Anastomosis Gastric Bypass (OAGB) on Type 2 Diabetic (T2D) Patients. Int J Environ Res Public Health. 2020; 17(20): 7644.

[6] Soong, Tien-Chou et al. 'Long-Term Efficacy of Bariatric Surgery for the Treatment of Super-Obesity: Comparison of SG, RYGB, and OAGB.' Obesity Surgery. 2021; 31(8): 3391-3399.

[7] Benotti P, Wood GC, Winegar DA, Petrick AT, Still CD, Argyropoulos G, Gerhard GS. Risk Factors Associated with Mortality after Roux-En-Y Gastric Bypass Surgery. Ann Surg. Jan 2014; 259(1): 123-30.

[8] Arakawa R, Febres G, Cheng B, Krikhely A, Bessler M, Korner J. Prospective Study of Gut Hormone and Metabolic Changes after Laparoscopic Sleeve Gastrectomy and Roux-En-Y Gastric Bypass. PLoS One. 2020; 15(7): E0236133.

[9] Malik VS, Willett WC, Hu FB. Global Obesity: Trends, Risk Factors and Policy Implications. Nat Rev Endocrinol. 2013; 9(1): 13-27. 
[10] Kolotkin RL, Meter K, Williams GR. Quality of Life and Obesity. Obes Rev. 2001; 2(4): 219-229.

[11] Sahoo K, Sahoo B, Choudhury AK, Sofi NY, Kumar R, Bhadoria AS. Childhood Obesity: Causes and Consequences. J Family Med Prim Care. 2015; 4(2): 187-192.

[12] Agha, Maliha, Riaz Agha. 'The Rising Prevalence of Obesity: Part A: Impact on Public Health.' International Journal of Surgery. Oncology. 2017; 2(7): E17.

[13] Montgomery JR, Waits SA, Dimick JB, Telem DA. Perioperative Risks of Sleeve Gastrectomy versus Roux-En-Y Gastric Bypass among Patients with Chronic Kidney Disease: A Review of the MBSAQIP Database. Ann Surg. 2021; 274(4): E328-E335.

[14] Topart P, Becouarn G, Ritz P. Biliopancreatic Diversion with Duodenal Switch or Gastric Bypass for Failed Gastric Banding: Retrospective Study from Two Institutions with Preliminary Results. Surg Obes Relat Dis. Sep- Oct 2007; 3(5): 521-5.

[15] Helmiö M, Victorzon M, Ovaska J, et al. Comparison of Short-Term Outcome of Laparoscopic Sleeve Gastrectomy and Gastric Bypass in the Treatment of Morbid Obesity: A Prospective Randomized Controlled Multicenter SLEEVEPASS Study with 6-Month Follow-up. Scand J Surg. 2014; 103(3): 175-181.

[16] Guerrier JB, Dietch ZC, Schirmer BD, Hallowell PT. Laparoscopic Sleeve Gastrectomy Is Associated with Lower 30-Day Morbidity Versus Laparoscopic Gastric Bypass: An Analysis of the American College of Surgeons NSQIP. Obes Surg. Nov 2018; 28(11): 3567-3572.

[17] Minhem MA, Sarkis SF, Safadi BY, Fares SA, Alami RS. Comparison of Early Morbidity and Mortality between Sleeve Gastrectomy and Gastric Bypass in High-Risk Patients for Liver Disease: Analysis of American College of Surgeons National Surgical Quality Improvement Program [Published Correction Appears in Obes Surg. 2018 May 14;]. Obes Surg. 2018; 28(9): 2844-2851.

[18] Zilberstein B, Santo MA, Carvalho MH. Critical analysis of surgical treatment techniques of morbid obesity. Arq Bras Cir Dig. 2019; 32(3): E1450.

[19] Lee JH, Nguyen QN, Le QA. Comparative Effectiveness of 3 Bariatric Surgery Procedures: Roux-En-Y Gastric Bypass, Laparoscopic Adjustable Gastric Band, and Sleeve Gastrectomy. Surg Obes Relat Dis. 2016; 12(5): 9971002.

[20] Nocca D, Guillaume F, Noel P, Picot MC, Aggarwal R, El Kamel M, Schaub R, de Seguin de Hons C, Renard E, Fabre JM. Impact of Laparoscopic Sleeve Gastrectomy and Laparoscopic Gastric Bypass on HbA1c Blood Level and Pharmacological Treatment of Type 2 Diabetes Mellitus in Severe or Morbidly Obese Patients. Results of a Multicenter Prospective Study at 1 Year. Obes Surg. Jun 2011; 21(6): 738-43.

[21] Salminen P, Helmiö M, Ovaska J, et al. Effect of Laparoscopic Sleeve Gastrectomy vs Laparoscopic Roux-En-Y Gastric Bypass on Weight Loss at 5 Years Among Patients With Morbid Obesity: The SLEEVEPASS Randomized Clinical Trial. JAMA. 2018; 319(3): 241-254.

[22] Zhang Y, Wang J, Sun X, et al. Laparoscopic Sleeve Gastrectomy versus Laparoscopic Roux-En-Y Gastric Bypass for Morbid Obesity and Related Comorbidities: A Meta-Analysis of 21 Studies [Published Correction Appears in Obes Surg. Jan 2015; 25(1): 27. Ju, Wang [Corrected to Wang, Ju]; Cao, Zhanguo [Corrected to Cao, Zhangou]; Xinsheng, Xu [Corrected to Xu, Xinsheng]; Daquan, Liu [Corrected to Liu, Daquan]; Xiangyang, Xin [Corrected to Xin, Xiangyang]]. Obes Surg. 2015; 25(1): 19-26.

[23] Puzziferri N, Roshek TB 3rd, Mayo HG, Gallagher R, Belle SH, Livingston EH. Long-Term Follow-up after Bariatric Surgery: A Systematic Review. JAMA. 3 Sep 2014; 312(9): 934-42.

[24] Celio AC, Wu Q, Kasten KR, Manwaring ML, Pories WJ, Spaniolas K. Comparative Effectiveness of Roux-En-Y Gastric Bypass and Sleeve Gastrectomy in Super Obese Patients. Surg Endosc. 2017; 31(1): 317-323.

[25] Cohen JB. Hypertension in Obesity and the Impact of Weight Loss. Curr Cardiol Rep. 2017; 19 (10): 98.

[26] Boido A, Ceriani V, Cetta F, Lombardi F, Pontiroli AE. Bariatric Surgery and Prevention of Cardiovascular Events and Mortality in Morbid Obesity: Mechanisms of Action and Choice of Surgery. Nutr Metab Cardiovasc Dis. 2015; 25(5): 437-443.

[27] Ashrafian H, Toma T, Rowland SP, Harling L, Tan A, Efthimiou E, Darzi A, Athanasiou T. Bariatric Surgery or NonSurgical Weight Loss for Obstructive Sleep Apnoea? A Systematic Review and Comparison of Meta-Analyses. Obes Surg. Jul 2015; 25(7): 1239-50. 
[28] Quintas-Neves M, Preto J, Drummond M. Assessment of Bariatric Surgery Efficacy on Obstructive Sleep Apnea (OSA). Rev Port Pneumol. Nov-Dec 2016; 22(6): 331-336.

[29] Sillo TO, Lloyd-Owen S, White E, et al. The Impact of Bariatric Surgery on the Resolution of Obstructive Sleep Apnoea. BMC Res Notes. 2018; 11(1): 385.

[30] Sarkhosh K, Switzer NJ, El-Hadi M, Birch DW, Shi X, Karmali S. The Impact of Bariatric Surgery on Obstructive Sleep Apnea: A Systematic Review. Obesity Surgery. 2013; 23(3): 414-423.

[31] Valezi, Antono, Herbella, Fernando, Schlottmann, Francisco, Patti, Marco. Gastroesophageal Reflux Disease in Obese Patients. Journal of Laparoendoscopic \& Advanced Surgical Techniques. 2018.

[32] Thaher O, Hukauf M, Stroh C. Propensity Score Matching Sleeve Gastrectomy vs. Gastric Bypass with 5 Years of Follow-Up. Obes Surg. 2021; 31(12): 5156-5165.

[33] Matar R, Maselli D, Vargas E, et al. Esophagitis after Bariatric Surgery: Large Cross-Sectional Assessment of an Endoscopic Database. Obes Surg. 2020; 30(1): 161-168.

[34] Peterli R, Wölnerhanssen BK, Peters T, et al. Effect of Laparoscopic Sleeve Gastrectomy vs Laparoscopic RouxEn-Y Gastric Bypass on Weight Loss in Patients with Morbid Obesity: The SM-BOSS Randomized Clinical Trial. JAMA. 2018; 319(3): 255-265.

[35] Barr AC, Frelich MJ, Bosler ME, Goldblatt MI, Gould JC. GERD and Acid Reduction Medication Use Following Gastric Bypass and Sleeve Gastrectomy. Surg Endosc. 2017; 31(1): 410-415. 